\title{
Increasing birth registration for children of marginalised groups in Pakistan
}

Iffat Idris

GSDRC, University of Birmingham

16 July 2021

\section{Question}

What type of interventions are effective for increasing the levels of birth registration for children from marginalised groups? Are there good examples from the global evidence base of 'inclusive' birth registration systems?

\section{Contents}
1. Summary
2. Birth registration
3. Reaching the most marginalised
4. Birth registration in Pakistan
5. References

The K4D helpdesk service provides brief summaries of current research, evidence, and lessons learned. Helpdesk reports are not rigorous or systematic reviews; they are intended to provide an introduction to the most important evidence related to a research question. They draw on a rapid deskbased review of published literature and consultation with subject specialists. other Government departments, but the views and opinions expressed do not necessarily reflect those of FCDO, the UK Government, K4D or any other contributing organisation. For further information, please contact helpdesk@k4d.info. 


\section{Summary}

Birth registration is a universal right - providing access to essential services, protection and other forms of identity - but globally, significant numbers of children remain unregistered. This stems from both supply-side and demand-side barriers, with marginalised groups facing additional challenges. Promoting birth registration requires a combination of supply- and demand-side measures. Effective approaches to reach marginalised groups, which have been used in various parts of the world, include outreach efforts to target such groups, integrating birth registration with health services, and integrating birth registration with safety net (cash transfer) programmes. Pakistan is one of the countries with especially low rates of birth registration (despite recent progress) - the PDHS $2017-18^{1}$ found that only $42 \%$ of children aged under five had their births registered. A promising digital initiative is being implemented in Punjab and Sindh provinces.

This review looks at approaches to promote birth registration among marginalised groups, in order to inform programming in Pakistan. It draws on a mixture of academic and grey literature, in particular reports by international development organizations. While there is extensive literature on rates of birth registration and the barriers to this, and consensus on approaches to promote registration, the review found less evidence of measures specifically aimed at marginalised groups. Gender issues are addressed to some extent, particularly in understanding barriers to registration, but the literature was largely disability-blind.

Key findings of the review are as follows:

- Importance of birth registration: birth registration is a fundamental human right, allowing access to services such as healthcare and education; it is the basis for obtaining other identity documents, e.g. driving licenses and passports; it protects children, e.g. from child marriage; and it enables production of vital statistics to support government planning and resource allocation.

- Barriers to birth registration mean many children are unregistered: globally, 166 million children under five are not registered (UNICEF, 2019: 16). Common problems are weak legal and policy frameworks; lack of coordination between different mandated agencies, and lack of interoperability between databases and information systems, complex and costly registration procedures, limited and under-resourced registration offices, lack of awareness and demand, and lack of prioritisation by government.

- Additional challenges facing marginalised groups: registration rates are generally lower than average for vulnerable children, e.g. from minority groups, migrants, refugees, children with disabilities. Discriminatory policies against minorities, restrictions on movement, lack of resources, and lack of trust in government are among the 'additional' barriers affecting the most marginalised. Women, especially unmarried women, also face greater challenges in getting births registered.

- General approaches to promoting birth registration: these broadly fall into supplyand demand-side measures, the former to increase accessibility and affordability of registration services, the latter to increase awareness and incentivise parents. Key

${ }^{1}$ National Institute of Population Studies and ICF (2019), Pakistan Demographic and Health Survey (PDHS) 2017-18, p. 14. https://dhsprogram.com/pubs/pdf/FR354/FR354.pdf 
examples are legal and policy reform, awareness-raising activities, capacity building of registration offices, integration of birth registration with health services/education/social safety nets, and use of digital technology to increase efficiency and accessibility.

- Outreach of registration services: Access issues are greater among marginalised (in remote rural locations, the poor, minorities facing discrimination, women, etc.) groups. Hence, one way to promote birth registration is to support outreach of registration services, specifically targeting such groups. This has been done in relation to: Roma communities in Albania using NGOs; internally displaced persons (IDPs) in Colombia using mobile registration facilities; and by building capacities of NGOs in Bangladesh to support registration of the most vulnerable and excluded children, including those of landless families, slum dwellers and minorities.

- Integration of birth registration and health services: this can be an effective way to overcome lack of capacity (offices, staff, funds) in national civil registration systems. Common approaches are placing registrars in health institutions, engaging health staff (e.g. midwives) as outreach registrars, and including birth registration components in public health campaigns (e.g. for immunization). There are numerous benefits: health services have broader coverage than civil registration offices, there are community-based health structures, and parents interact with health facilities already.

- Successful examples of this approach are seen in The Gambia, Uganda, Mozambique and Ghana. In the latter birth registration was tied in with annual child health promotion weeks and community health workers were trained to register births. As well as bringing about a significant rise in birth registration, the Ghanaian campaign reduced inequalities on the basis of rural-urban residence, socioeconomic status and access to health facilities. In Bangladesh birth registration of under-five children greatly increased as a result of its inclusion in the nationwide expanded programme of immunization (EPI).

- Incentives through links with safety net programmes: Eliminating barriers to birth registration may not be enough to generate demand, but incentives can do this. Common incentives are tying birth registration to education access, and to social transfers. Birth registration has been promoted, e.g. in Brazil, by making it a requirement to access cash transfers (in Brazil's case, the Bolsa Familia programme). In South Africa similar results were achieved by making it a condition to obtain Child Support Grants. However, in both Brazil and South Africa, efforts to incentivise demand were accompanied by reforms to the registration system to ensure the increased demand could be met. Furthermore, people should not be deprived of benefits or rights because of lack of registration. There are also examples of unconditional cash transfers (with no requirement for birth registration) helping promote this.

- Pakistan has low levels of birth registration: despite being necessary for issuance of national identity cards and passports, levels of birth registration are low. $9 \%$ of the world's 166 million unregistered children are in Pakistan (UNICEF, 2019: 16). While progress has been made in recent years, gaps remain, and some population groups have been left behind, including the poorest households, and those speaking languages other than Urdu and Punjabi (i.e. minority ethnic groups). There are significant interprovincial and rural-urban disparities in birth registration, as well as across wealth quinitiles. The Digital Birth Registration (DBR) is a promising initiative in Punjab and Sindh provinces, which uses facilitators (e.g. lady health workers and nikah registrars) 
who directly access families with newborns and mobile technology to enter data for birth registration.

\section{Birth registration}

\section{Importance}

Birth registration provides formal recognition by a state of a child's birth and is a permanent and official record of a child's existence (UNICEF, cited in Plan, n.d.: 6). Without it, in the eyes of the law, children are invisible, and hence could be denied access to essential services, or lack essential protection from exploitation. Birth registration is important because (Plan, n.d.: 6, 8):

- Birth registration is a fundamental human right - It is enshrined in the UN Convention on the Rights of the Child, which states that: 'every child shall be registered immediately after birth and shall have the right from birth to a name and a nationality'. It is also included in the 2030 Agenda for Sustainable Development: Target 16.9 aims to provide legal identity to all, including birth registration, by 2030. The Regional Action Framework on Civil Registration and Vital Statistics for Asia and the Pacific (which includes Pakistan) has an agreed goal of universal civil registration of births, deaths and other vital events. ${ }^{2}$

- It allows access to services - including health care, education and social protection.

- It protects children - birth registration helps prevent children being forced into marriage or into the informal labour market before the legal age: 'how to enforce laws on child marriage or child labour when a child's age cannot be verified?'

- It is the basis for access to other vital legal identity documents - birth registration provides a first form of legal identity, upon which other forms can be obtained, e.g. national ID cards, passports, and driving licences. These in turn are vital for many functions, e.g. voting, opening a bank account, getting formal employment, registering property, getting a mobile phone.

- It enables production of vital statistics - Birth registration, along with recording and documenting of other life events such as marriage, divorce, adoption and death, into a civil registration and vital statistics system (CRVS) system, is a fundamental function of governments. These statistics are essential in understanding population dynamics, allocating resources, planning and implementing development programmes, and measuring progress in human development.

\section{Challenges}

Birth registration levels remain very low. Globally, the proportion of children under five with a registered birth increased from 58\% in 2000 to $65 \%$ in 2015 (Suthar et al, 2020: 4). Despite this, the births of 166 million children under the age of five have not been registered (UNICEF, 2019: 16). Of these, half live in just five countries: India, Nigeria, Ethiopia, Pakistan and the Democratic Republic of Congo (UNICEF, 2019: 16). In Sub-Saharan Africa, for example, less than one in two https://www.unescap.org/sites/default/files/Asian_and_Pacific_Civil_Registration_and_Vital_Statistics_Decade20 15-2024_Booklet.pdf 
children under five are registered (UNICEF, 2018). South Asia is home to the largest share of children under five without a birth certificate (UNICEF, 2019: 18). UNICEF warn that, at current trends, 115 million children will be left without access to a legal identity by 2030 (UNICEF, 2018b).

Among the most common problems hampering birth registration are (World Bank, 2016: 3-4; Plan, n.d.: 11-13):

- Weak legal and policy framework - laws and policies can be outdated, not reflecting UN standards, or discriminatory, e.g. preventing women, ethnic or religious minorities, and non-nationals or children of non-nationals from being registered.

- $\quad$ Lack of coordination - different laws could support different CRVS components, making it hard to govern CRVS activities in a coordinated manner. The mandate for CRVS could sit with different ministries at national level, or be decentralised with limited national level oversight - both of which can lead to work being done in isolation rather than in a coordinated way. Moreover, different government departments may have different and sometimes conflicting policies and procedures.

- $\quad$ Lack of interoperability - Databases and information systems for managing information often vary across sectors, such as health, education, and social protection, and these databases are often not interoperable, leading to fragmented and inefficient processes.

- Supply side procedures and systems - birth registration procedures can be complex and costly. Lack of registration centres/mobile registration services make access for parents difficult. Lack of digitisation leads to inefficiency, difficulties in sharing information between agencies, and issues like loss/damage to paper records. Registration offices can be understaffed and under-resourced, and lack capacity - contributing to low registration rates or inadequate capturing and processing of birth registration data.

- $\quad$ Lack of awareness and demand - people might not be aware of the benefits of birth registration, and discouraged by the direct (e.g. fees) and indirect (e.g. travel expense and time) costs involved. Sociocultural norms, e.g. preference for male children, could lead to some groups, e.g. girls, not being registered. Cultural or religious practices (e.g. time needed before a name can be chosen) could also lead to delay in registering births.

- Lack of prioritisation by governments - reflected in lack of resources and personnel for birth registration, and lack of monitoring of performance (weak accountability mechanisms).

Vulnerable and marginalised groups face particular problems in birth registration. Registration rates are generally lower than average for vulnerable children, including: urban slum-dwelling children; children from minority groups, migrant, refugee and IDP populations; children who are stateless, disabled, or orphaned; and children born during or just after wars or natural disasters (UNICEF, 2013b: 42). A number of factors are involved (World Bank, 2016: 3 \& 10):

- Distance to registration facilities is especially a challenge for poor, rural, or geographically isolated populations, both in terms of opportunity (e.g. lost earnings) and travel costs.

- Migrants with limitations on freedom of movement may be prevented from registering a birth because they can't access a registration point.

- Women are often marginalized, especially if they are not married when trying to register their children. Unmarried mothers (of children born out of wedlock) may fear shaming and 
not wish to register their child. Some countries denote that children are born to unmarried mothers on the birth certificate, which can deter registration out of fear the child will be stigmatized.

- In some countries, the father is legally responsible for registering the birth of a child; if a father is absent or the identity of the father is unclear, a mother is unable to register her child.

- About 60 countries maintain nationality laws that discriminate based on sex, and more than 20 countries deny women the equal right to confer their nationality to their own children.

- Discriminatory policies against minorities may prevent certain populations from registering a child. At least 20 countries have nationality laws that permit denial, loss, or deprivation of nationality on discriminatory grounds.

- Lack of trust in government, especially among refugee or formerly persecuted ethnic minorities reduces registration.

- Many children born to stateless parents are unable to be registered, perpetuating the cycle of non-registration and statelessness.

- Some countries refuse to register the children of refugees, asylum seekers and noncitizens without permanent residence.

The above list clearly highlights the challenges faced by women. Many obstacles to registration affect both men and women, e.g. poverty, distance to registration services, lack of education. But 'women and girls in particular face a vicious cycle of exclusion from civil registration due to the way these barriers interact with and reinforce social and cultural factors, such as a lack of autonomy, limited agency, power imbalances, and harmful practices' (AbouZahr et al, 2019: 3). For example, registration offices are often hard to access for people living in rural areas, but they are particularly inaccessible to women who may have restricted financial independence and freedom of movement due to local customs and household responsibilities (AbouZahr et al, 2019).

\section{Approaches to promoting birth registration}

Approaches to promote birth registration are geared towards addressing the various barriers faced, and broadly fall into supply- and demand-side measures. Supply-side measures are focussed on increasing accessibility, acceptability and/or affordability of registration services, while demand-side measures are focussed on increasing awareness for registration through information, education, communication and/or advocacy. Being inclusive and gender-sensitive is important in all approaches. Key measures include (Muzzi, 2010):

- Legal reform to ensure laws are in line with international standards, and birth registration is free of charge and conducted immediately after birth.

- Adequate policies, plans of action and strategies to implement functioning routine national birth registration systems.

- Awareness-raising activities, e.g. through national mass media communication (TV, radio and print) and community mobilization. Also, production of information, education and communication materials in local languages.

- Registrar training and capacity building of registry offices.

- Integration of birth registration with health services (see below). 
- Registration campaigns in schools and partnerships with Ministries of Education - these can be particularly beneficial in clearing backlogs of unregistered children of school age.

- Online/computerized birth registration systems to increase efficiency and accessibility.

- Penalties (e.g. additional fees for late registration) and incentives (e.g. making birth registration a requirement to access cash transfer programmes).

A systematic review of policies to improve birth and/or death registration identified 35 articles documenting experience in 25 countries representing all global regions (Africa, the Americas, Southeast Asia, the Western Pacific, Europe and Eastern Mediterranean) (Suthar et al, 2020). It found that combination policy approaches, consisting of at least a supply and demand component, were consistently associated with improved registration rates in different geographical contexts. Caveats are that there were limited articles on Europe and the Eastern Mediterranean, and there was a risk of publication bias (some countries have not documented their experience, in particular for policies that had neutral or negative effects). This points to the need for further research and evaluation to understand which policies do not work. The authors also caution about the interpretation of the results (Suthar et al, 2020: 12-13):

For example, an intervention implemented on a subnational scale may face different operational issues and a different direction of effect when implemented nationally. One example of this is use of community-based registration services. This type of policy would be useful to fill a geographic void in rural settings but may prove redundant in many urban settings. Furthermore, in areas with poor telecommunication platforms and connectivity, mobile registration fills a void; however, in facilities that have computers with connectivity, it may prove redundant.

The review stresses the need to understand barriers to birth registration to identify which policy approaches are most appropriate.

\section{Reaching the most marginalised}

This review focuses on approaches to reach the most marginalised and vulnerable groups in society. A number of case studies are given, showing the effects of different approaches in promoting birth registration among such groups.

\section{Outreach of registration services}

As noted, one of the main barriers to birth registration is lack of access to registration facilities typically, because these are located far away, and significant cost and time is involved for parents in reaching them and registering their children. Access issues are greater among marginalised (in remote rural locations, the poor, minorities facing discrimination, women, etc.) groups. The examples below illustrate efforts to reach out to marginalised groups and promote birth registration of their children.

\section{Roma in Albania}

In Albania, Roma communities have lower rates of birth registration than the wider population, with the knock-on effect that Roma children and adults face difficulties in accessing services later in life. To address this issue, UNICEF mobilized non-governmental partners to provide birth 
registration paperwork and services to Roma communities and other marginalized groups whose rates of birth registration fall below the national average (UNICEF, 2013a: 8). UNICEF also supported a geo-mapping of the known 108 Roma communities, to identify the locations, maternity homes and civil registry offices where children are born but not registered (UNICEF, 2013b: 101). The agency has been working with the Ministry of Health and the Civil Registry to establish a system where the records of these maternity homes are electronically linked to those of the Civil Registry. This is expected to allow for the identification of children who require their births to be registered, and to reduce the incidences where birth registration does not take place due to errors in filling in the required information, and to an overall improvement in the quality of child health statistics of the country (UNICEF, 2013b: 101).

\section{Colombia}

In Colombia due to the location of registration services - initially only available in urban centres vulnerable populations, such as internally displaced people (IDPs) from the protracted conflict in the country, were regularly found without a birth certificate or proof of identity. To tackle this, the National Registry of Civil Status (RNEC) was strengthened to assist birth registration among IDPs and other such vulnerable groups. UNHCR, Plan International and partners supported the Vulnerable Population's Attention Unit (UDAPV) under the RNEC. Set up in 2004, this unit has the capability to immediately provide birth registration, identity cards for children and adolescents and provisional identity documents. UDAPV services are supported by three types of mobile units (PLAN, n.d.: 36):

- Mobile offices (large vehicles) that have the technical equipment required to carry out the provision of birth certificates.

- "Light units" (4x4 vehicles) for access to more remote areas that carry all equipment but require installation in a location.

- Mobile Kits: hardware and software equipment required to issue birth certificates. Easy to transport and install, allowing staff to provide birth certificates almost anywhere.

Five years after its creation within RNEC, a resolution passed on 31 July 2009, stated that UDAPV would now assume 'the effective and timely coordination, programming, and execution of the more vulnerable campaigns in the farthest regions of the national territories' (PLAN, n.d.: 6). As a result, the structures, management and sustainability of these services have been ensured. During implementation, institutional adjustments within RNEC and innovations in the regulations have helped ensure UDAPV's success. These include use of 'ad hoc' registrars: specially commissioned registrars who accompany the campaign so Municipal Registrars can continue their day-today work. Also, RNEC's leading role in ensuring enough financial resources for UDAPV so it isn't dependent on funding from international partners - thereby ensuring its sustainability.

\section{Bangladesh}

Various steps have been taken in Bangladesh to increase birth registration in the general population, notably integration of birth registration with public health campaigns (see below), as well as legal reforms and use of technology. In addition to these measures for general national application, special initiatives were undertaken to register the most vulnerable and excluded children. These include children of landless families, children living in slums, sexually exploited 
children in brothels and children of other marginalized groups, such as certain minorities (Muzzi, 2010: 23). NGO partners working with these children and adolescents at risk were included by UNICEF in training and awareness-raising activities on birth registration to help reach all children. Steps were taken to identify NGOs, build their capacities and establish their connections and networking with various government departments to facilitate a coordinated effort in registering the most vulnerable population. UNICEF was supporting the Government of Bangladesh to register births of Rohingya refugee children born in Bangladesh, and another special initiative was underway to register Gypsy children in the country (Muzzi, 2010: 24).

\section{Integration with health services}

Considering national civil registration systems' lack of outreach capacity and human and financial resources, Muzzi (2010) argues that integrating birth registration into health services is perhaps the most effective approach to ensure children are registered. Three common approaches to integrating birth registration and health services are (Muzzi, 2010: 10):

- Placing civil registrars in health institutions (i.e., hospitals, maternity wards, primary health centres, etc.)

- Engaging community health officers and midwives as outreach registrars

- Including a birth registration component in public health campaigns (i.e., immunization, anti-malaria, etc.).

The benefits for a birth registration system in partnering with the health sector, instead of maintaining the status quo of most countries where civil registrars act as stand-alone institutions, include the following (Muzzi, 2010: 10-11):

- Health services have broader coverage than civil registration offices since their services include outreach facilities, such as antenatal clinics (ANC) and an expanded programme on immunization (EPI), and community-level services (such as primary health care (PHC) clinics, growth monitoring programmes, etc.).

- The Ministry of Health $(\mathrm{MoH})$ is in a position to encourage patients to register births, register children and monitor birth registration through its health facilities and programmes, such as prenatal care, immunization campaigns and vitamin A supplementation.

- In many countries, the $\mathrm{MoH}$ maintains reliable and up-to-date records on births and deaths. It records important details related to identification of a child in its Birth Delivery Book, as well as on child immunization cards or growth monitoring cards.

- The community-based structures of the $\mathrm{MoH}$ often include health posts, community health workers and trained traditional birth attendants (TTBA), and allow health services to be delivered as close to the population as possible, unlike civil registration offices in most countries.

- The use of health facilities and frequent contacts between caregivers of young children and health services will help to reduce parents' and guardians' service costs.

- Integrating birth registration and health services is also an effective approach in conflict and post-conflict situations, as health services are often the only functioning emergency service for children in these circumstances. 


\section{Ghana: incorporation of birth registration in health sector}

Birth registration rates among children under five years increased in Ghana from $44 \%$ to $71 \%$ between 2003 and 2008 (Fagernas \& Odame, 2013: 459). This compares to an average rate of 49\% in the period 2004-10 among 30 other Sub-Saharan African countries, with only a few making any notable progress (Fagernas \& Odame, 2013: 459). Ghana therefore stands out as a success story. It came about because of a campaign conducted from 2004, which entailed a number of different interventions.

Key barriers to birth registration in Ghana included the absence of registration offices in rural areas, a shortage of registration staff, and the direct costs (fees) and indirect costs (time off work, travel expenses) involved - the latter disproportionately affected poorer areas. The 2006 Multiple Indicator Cluster Survey (MICS) found that the main reasons for not registering were high cost of registration (31.9\%), distance to registration locations $(21 \%)$ and lack of awareness that children should be registered (20\%). The birth registration campaign focused on these factors, carrying out the following measures (Fagernas \& Odame, 2013: 460):

- From mid-2003 the legal period for free registration of infants was extended from 21 days to one year. Otherwise, late registration carries a fee;

- To promote public education, the first annual Birth Registration Day was held in September 2004, in which 10,000 children were registered across the country;

- Since 2004, the Births and Deaths Registry has participated in annual child health promotion weeks organized by the Ghana Health Service in May and November;

- Community health workers were trained to register births, offering services in community health clinics and also on a mobile basis;

- Mobile community registration volunteers were introduced to register births, especially in remote areas;

- Community population registers were piloted in 21 remote communities in four regions.

As noted, the campaign led to a significant rise in birth registration in Ghana. What is particularly significant is that it reduced inequalities in birth registration on the basis of rural-urban residence and socioeconomic status, and weakened the association between birth registration and access to health care at birth or subsequent access to health facilities. For example, in 2003 the likelihood of having been registered was 12 percentage points lower for a child born at home than for one born in a health facility; in 2008, this likelihood was only 5 percentage points lower. Figure 1 illustrates the estimated contribution of specific factors on the likelihood of registration. As seen, vaccinated children were more likely to have been registered both before the campaign and subsequently. Vaccination could take place not only during health centre visits, but also through community health workers as well as mobile services and outreach health activities. 
Fig. 1: Association between access to health care, household wealth quintile and urban/rural residence status on the probability of birth registration in Ghana in 2003 and 2008

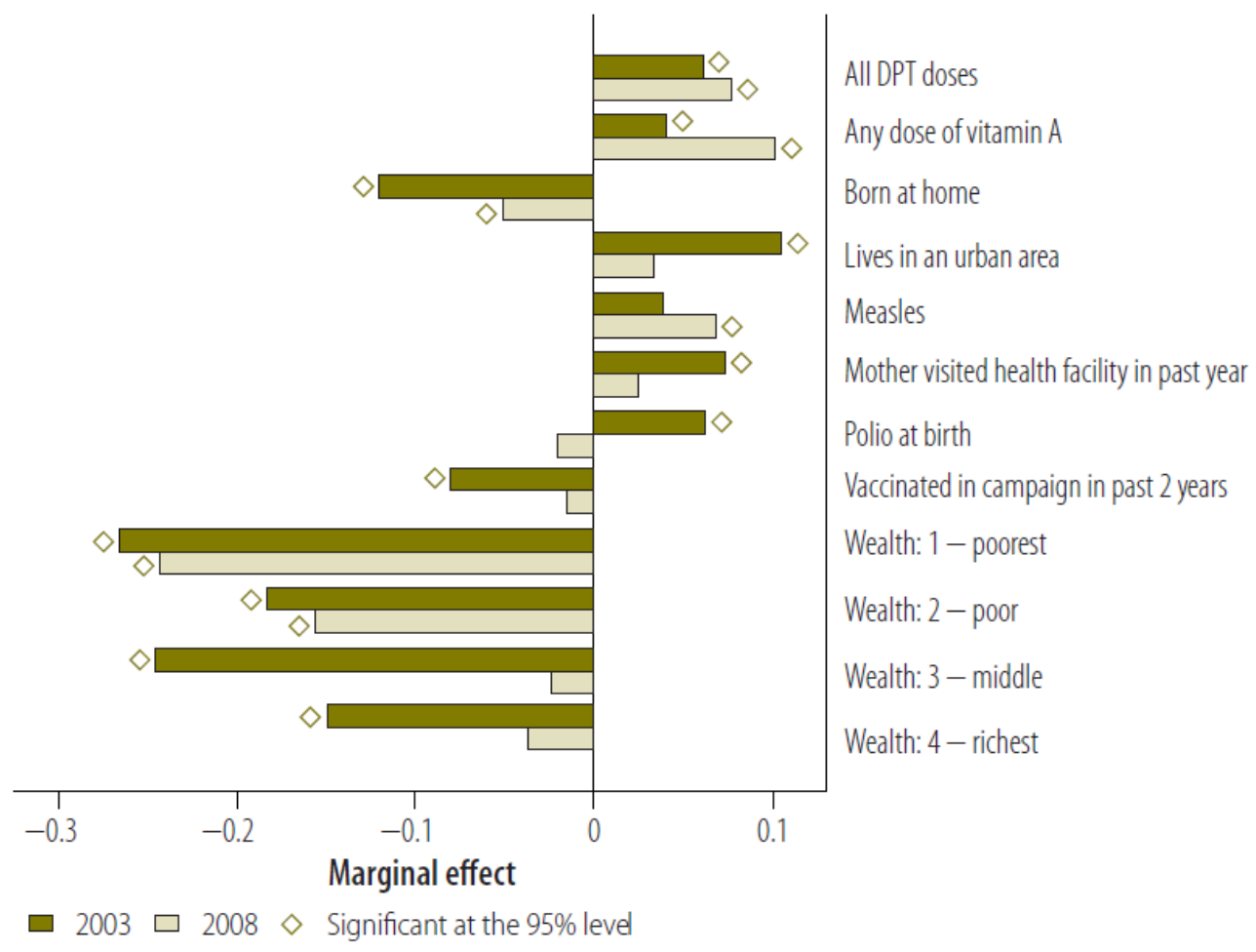

Source: Fagernas \& Odame, 2013: 461, licensed under CC BY-NC-SA 3.0 IGO

In their assessment of the effectiveness of the Ghanaian campaign to boost birth registration, Fagernas and Odame (2013: 462) identified the following main lessons learnt:

- The incorporation of birth registration into community health care, health campaigns and mobile registration activities have increased birth registration in Ghana by reducing the indirect costs of birth registration, especially in poorer communities;

- The links between health sector and birth registration should be strengthened further, ideally by locating registration facilities within all health facilities;

- In more remote areas, local community population registers should be actively encouraged to expand registration coverage.

\section{Other examples}

Examples of results from collaboration between the civil registrar and health sectors, implemented with UNICEF support in 29 countries between 2006 and 2008, include (Muzzi, 2010: 8):

- In the Gambia, integration of birth registration into reproductive and child health services, meant coverage reached $90 \%$ of the country's children and resulted in an increase of birth registration rates for children under-five, from 32\% in 2000 to 55\% in 2005.

- In Uganda, the integration of birth registration on 'child health days' cleared over $70 \%$ of the backlog of unregistered children. 
- In Mozambique, a community-based routine birth registration system was established within the framework of the national Accelerated Child Survival and Development strategy, and reached over 800,000 children ( $8 \%$ of all children in Mozambique).

- In Bangladesh, birth registration of under-five children increased from 10\% in 2006 to $40 \%$ in 2008 as a result of its inclusion in the nationwide expanded programme on immunization (EPI) in 2005. The success of this approach led to the expansion of this component into the new Hib pentavalent vaccine in 2009. In addition, in order to introduce electronic birth registration in the country, the Government developed the Birth Registration Information System software package in 2002. This system was expanded to include an electronic immunization administration system that resulted in increased birth registration and immunization rates.

\section{Integration with social protection}

Incentives are policies that encourage citizens to register a birth. Research has shown that eliminating barriers may not be enough to spur parents to act, but providing incentives for registration can modify their cost-benefit analyses and change their behaviour (World Bank, 2016: 5). Two commonly used forms of incentives are education, where schools may require a child to be registered to attend school, and social transfers (UNICEF, 2013b: 66). Cash transfers, for example, often target the poorest in society, and often require or support beneficiaries to be registered as a means of establishing their identities. Use of social transfer programmes has been rapidly expanding in many parts of the world.

Conditional cash transfers (CCTs) require participants to meet certain conditions to receive the transfers, while unconditional cash transfers (UCTs) have no such requirements. The requirement of beneficiaries to provide proof of birth registration of household members to enrol in social protection programmes can act as a catalyst to increase birth registration.

\section{Brazil}

Brazil's efforts to combat poverty and reform of social policy in the 1990 s and 2000 s created significant social transfer programmes. Started in 2014, Bolsa Familia is the largest CCT programme in the world, providing between US $\$ 5$ and US $\$ 30$ per month (depending on monthly per capita income): by 2014 it had supported 50 million Brazilians, approximately one quarter of the population (World Bank, 2016: 7 \& 9). One of the administrative requirements for beneficiaries is identity documentation. Many Brazilians have obtained birth certificates specifically to meet this requirement - it acts 'as a concrete registration incentive to the poor' (World Bank, 2016: 7). In 1998, 27.1\% of births were unregistered in Brazil, but by 2012 this figure had dropped to 6.7\% (World Bank, 2016: 7). Critically, as well as setting up cash transfers with the requirement for birth registration, the Brazilian government also carried out various policy reforms to ensure that the demand for identity documents was met - 'making the Brazilian case a strong example for how to increase birth registration' (World Bank, 2016: 18).

\section{South Africa}

South Africa has seen a spectacular rise in birth registration within the first year of life, increasing from 24\% in 1991 to $50 \%$ in 2001, 75\% in 2005 and 95\% in 2012 (UNICEF, 2013a: 33). A major incentive to early registration has been the requirement that a birth certificate be presented in order to obtain social protection grants, including a Child Support Grant. South Africa's Child 
Support Grant is a nationwide cash transfer to households under the government-determined income threshold (World Bank, 2016: 7). Studies show the grant is a significant contributor to increasing the country's birth registration rate (World Bank, 2016: 7).

However, the literature highlights the reorganization of the CRVS system in South Africa and creation of registration infrastructure, alongside financial incentives and public awareness campaigns. Government efforts focused on addressing the needs of rural communities by establishing fixed service centres as well as hospital registration points, mobile units and MultiPurpose Community Centres. As with Brazil, South Africa ensured that demand-side incentives for birth registration were accompanied by supply-side measures to meet the increased demand.

\section{Other examples}

A World Bank literature review on incentives for improving birth registration coverage identified other countries in which cash transfer programmes have impacted birth registration rates (World Bank, 2016: 6-7):

- Bolivia's Bono Juancito Pinto, a cash transfer to families with children in public schools, stimulated demand for birth registration, contributing to the increase in Bolivia's national birth registration rate from $74 \%$ in 2001 to $87 \%$ in 2011 .

- The birth certificate requirement of Nepal's Child Grant increased birth registration of children in the area the grant supports to $90 \%$, while the national birth registration rate of Nepal was $42 \%$.

- Lesotho's Child Grants Program increased birth registration by 37 percentage points.

- Two CCTs, one in Zimbabwe and one in India, mandated birth registration as a condition of the programmes, in addition to other child-related conditions. Compared to control groups, rates of birth registration or certification increased by between 14 and 17 percentage points for the children of the beneficiary households of both the CCTs. The Zimbabwean CCT resulted in the registration rate of the beneficiaries' children aged 0-4 increasing by 16.4 percentage points compared to the control group, and the registration rate of school-aged children increasing by 15 percentage points. The Indian Majoni scheme increased the number of applications for registration of female children in the area of the CCT by nearly 15 percentage points.

The World Bank review (2016: 8) stresses that cash transfer programmes with birth registration requirements are successful when they simultaneously strengthen and streamline the birth registration and cash transfer services. Conversely, it warns of the risks in linking cash transfers to birth registration, noting that 'the conditions and administrative requirements of the programs have the potential to act as barriers and prevent the most vulnerable from accessing valuable social welfare programs. Inadequate access to registration services has hindered potential beneficiaries from registering births and meeting the requirements of many cash transfer programs' (World Bank, 2016: 8).

This point is echoed by UNICEF (2013b: 66), which stresses that the requirement for birth registration should not be used to deny people access to other benefits or rights:

Critical here is that the lack of access to one right should not hinder a child's ability to access another right. While, through the interoperability of the child protection system, another service may promote birth registration, it should also not be used to deny 
children their access to a right. If the ability to access a service or avail oneself of a right is tied, by law, to being registered, then the State has an obligation to ensure that barriers to registration are removed, and that those who were not registered at birth have the means to register later in life.

In the above cases, CCT programmes were strong financial incentives for parents to change their behaviour and register their children. But some cash transfer programmes facilitated birth registration even without an explicit behavioural compliance condition (World Bank, 2016: 7):

- Colombia's cash transfer programme, Familías en Acción, had local officers from the national registration agency present when new beneficiaries enrolled in the programme. When programme officials checked on expectant mothers enrolled in the programme, they encouraged mothers to register their newborns. The rate of children with birth certificates was $97.3 \%$ of participant children compared to the $91.7 \%$ of non-participant children.

- Kenya's Orphan and Vulnerable Children's programme is technically a CCT, but the conditions do not include birth registration. In addition, the enforcement of the conditions varies, as some households may live in communities that have limited access to the objective of the programme, and it has been shown to increase the rate of children with birth certificates by 11 percentage points.

The World Bank review notes that cash transfer programmes that were not contingent upon birth registration often did not act as registration incentives. Rather, the additional money, increased awareness, and registration assistance eliminated registration barriers (World Bank, 2016: 7).

\section{Birth registration in Pakistan}

\section{Levels and inequalities}

Birth registration is necessary for all children in Pakistan. Without it they cannot obtain a birth certificate, which is required for the issuance of national identity cards (NIC) and passports.

Levels of birth registration are low. Of the 166 million children under five who are unregistered in the world, 9\% are in Pakistan (30\% in South Asia) (UNICEF, 2019: 16). UNICEF reported a national rate for Pakistan of $27 \%$ in 2013, compared to the regional average for South Asia of $39 \%$ - itself among the lowest in the world (UNICEF, 2013a: 17). The PDHS 2012-13 reported a slightly higher rate of $33 \%$, but this is still low. ${ }^{3}$ Since then, the regional average has risen to around $70 \%$, driven largely by improvements in Bangladesh, India and Nepal, but Pakistan lags behind (UNICEF, 2019: 29).

According to the Pakistan Demographic and Health Survey (PDHS) 2017-18, 57.8\% of children aged under five years in Pakistan were unregistered (Boiteau-Monteville, 2020: 1). Compared to the previous PDHS 2012-13, this represented a rise from $32.9 \%$ to $43.2 \%$ for children under five, and a rise from $39.1 \%$ to $50.7 \%$ for children under 18 in the four main provinces and Islamabad

\footnotetext{
${ }^{3}$ National Institute of Population Studies and ICS (2014), Pakistan Demographic and Health Survey 2012-13, p.
} 20. https://dhsprogram.com/pubs/pdf/FR290/FR290.pdf 
Capital Territory (ICT) (Boiteau-Mondeville, 2020: 2). While Pakistan has made significant progress in its birth registration completeness in recent years, numerous gaps remain (BoiteauMondeville, 2020).

Moreover, progress has not been uniform, leaving some groups of the population behind. A comparison of the PDHS 2012-13 and PDHS 2017-18 shows that (Boiteau-Mondeville, 2020):

- In both surveys, the furthest behind in birth registration were children belonging to households in the bottom $40 \%$ for wealth, and whose household language was Balochi, Pushto, Seraiki, Sindhi or other. In these households the registration rate was $7 \%$ in 2012-13 and 15\% in 2017-18;

- By contrast, children from households speaking these same languages but in the top $60 \%$ for wealth saw their birth registration rate increase from $36 \%$ to $51 \%$;

- Among children from Punjabi- or Urdu-speaking households in the top $60 \%$ for wealth, the registration rate went from $64 \%$ to $79 \%$.

- With regard to socioeconomic status, the highest progress was seen in the middle three quintiles, while both the poorest and richest quintiles saw lower progress.

Further examination of the data shows that most of the factors considered as potential drivers of inequality are associated with significant variations in registration rates: the higher the wealth quintile, the higher mother's educational attainment, and possession of an NIC card by the mother all increase the chances of children being registered (Boiteau-Mondeville, 2020).

Boiteau-Mondeville (2020) concludes that the results are in line with the expectation of households from higher social classes having easier access to birth registration and being more conscious of its benefits, and highlights the need for authorities to initiate specific actions to make registration procedures more accessible to the groups left out. He notes that, while 'minority' language speakers generally have lower birth registration rates, in Balochistan the rate greatly increased from one survey to the next - suggesting it is 'not a hopeless situation'.

Of the various approaches to promoting birth registration outlined above, relevant points in the literature in relation to Pakistan include:

- Integration of civil registration with health services - under Pakistan's National CRVS Policy, twinning with the health sector for notification is the way forward for national scale-up.

- Promoting access of women to registration services - in some areas of northern Khyber Pakhtunkhwa, women registration centres were established by the government as males in the communities were reluctant to have male staff in the centres interacting with female community members, particularly for taking biometric thumb impressions which involve physical contact.

- Integration with social protection initiatives - there is currently significant interest in Pakistan on the part of government in large-scale social protection nets, and could be an effective way to reach out to those below the poverty line to carry out birth registration. 


\section{Digital Birth Registration (DBR) initiative}

In 2014 the Digital Birth Registration (DBR) was launched as a pilot in Sindh and Punjab to increase birth registration rates. It was implemented by UNICEF, the Departments of Local Government and Health, the National Database Registration Authority (NADRA) and mobile telecom network operator Telenor. The latter developed an app for use by health workers (notably, lady health workers or LHWs) and marriage (nikah) registrars. The initiative involves authorised personnel visiting homes and logging details of newborns on their mobile phones. Alternatively parents can visit DBR franchises - Telenor distribution centres - where facilitators enter their data on the app. Data fed in includes the date and time of the child's birth, parents' names and NIC numbers, address and photos of NIC cards. This data is transferred to the Union Council office for verification, and then uploaded into the UC office database and issued a Civil Registration Management System (CRMS) number (NADRA unique ID). Parents can then collect the birth certificate. When they do this, the data is transferred from the UC office to the provincial office of NADRA and then to its head office as a permanent record (Malik, 2016).

The pilot phase led to an increase in birth registration from $30 \%$ to $90 \%$ in just six months, with nearly $50 \%$ of registered children being girls (Telenor, n.d.). In one Union Council in Sindh Dhabeji $-95 \%$ of children were registered within the first six months of their birth in 2015 , compared to approximately 5\% in 2014 (Malik, 2016). The project was later scaled up to cover nine districts of Punjab and Sindh, aiming to register 700,000 children by the end of 2018 (Telenor, n.d.). PLAN International also supported later rollout of the DBR initiative. As well as increasing birth registration, the system allowed for a gradual transformation to a robust digital civil registration database - a key tool for the government to plan more effectively for all services for children, including vaccination programs and education, as well as establishing legal protection from abuse and exploitation (PLAN, 2017). 


\section{References}

AbouZahr, C. et al. (2019). Making Civil Registration and Vital Statistics Systems Work for Women. Knowledge Brief Series on Gender and CRVS, Centre of Excellence for Civil Registration and Vital Statistics (CRVS) Systems. https://crvssystems.ca/sites/default/files/inlinefiles/CRVS_Gender_2.4_Empower_e.pdf

Boiteau-Monteville, U. (2020). 'Birth registration inequalities: A case study of Pakistan'. UNESCAP.

https://www.unescap.org/sites/default/files/APS2020/43_Birth_registration_inequalities_case_stu dy_of_Pakistan_Ulysse_ESCAP.pdf

Fagernas, S. \& Odame, J. (2013). 'Birth registration and access to health care: an assessment of Ghana's campaign success'. Bulletin of the World Health Organization, 2013 (91): 459-464.

https://www.who.int/bulletin/volumes/91/6/12-111351.pdf

Malik, A. (2016). 'Boosting birth registration in Pakistan with mobile phones'. UNICEF, 1 April 2016. https://www.unicef.org/stories/boosting-birth-registration-pakistan-mobile-phones

Muzzi, M. (2010). UNICEF Good Practices in Integrating Birth Registration into Health Systems (2000-2009). Case studies: Bangladesh, Brazil, The Gambia, and Delhi, India. UNICEF. https://www.unescap.org/sites/default/d8files/knowledge-products/UNICEF-birth-registration-inhealth-systems.pdf

PLAN International (2017). 'Smart phone app to revolutionise the birth registration system in Pakistan', 6 September 2017. https://getinthepicture.org/news/smart-phone-app-revolutionizebirth-registration-system-pakistan

PLAN International \& Accenture (n.d.). Innovations in Birth Registration. https://planinternational.org/early-childhood/birth-registration

Suthar, A. et al (2019). 'Evaluation of approaches to strengthen civil registration and vital statistics systems: A systematic review and synthesis of policies in 25 countries'. PLoS Med 16(9). https://journals.plos.org/plosmedicine/article?id=10.1371/journal.pmed.1002929

Telenor (n.d.). 'Giving Pakistani children an identity'.

https://www.telenor.com/sustainability/digital-birth-registration/giving-pakistani-children-anidentity/

World Bank (2016). Incentives for improving birth registration coverage: A review of the literature. http://documents1.worldbank.org/curated/en/928651518545413868/Incentives-for-ImprovingBirth-Registration-Coverage-A-Review-of-the-Literature.pdf

UNICEF (2013a). Every Child's Birth Right: Inequities and trends in birth registration. United Nations Children's Fund.

https://www.unicef.org/media/files/Embargoed_11_Dec_Birth_Registration_report_low_res.pdf

UNICEF (2013b). A Passport to Protection. A Guide to Birth Registration Programming. United Nations Children's Fund. https://www.refworld.org/docid/52b2e2bd4.html 
UNICEF (2018a). Status of Civil Registration and Vital Statistics in South Asia Countries 2018. United Nations Children's Fund.

https://www.unicef.org/rosa/media/3121/file/UNICEF\%20ROSA\%20Status\%20of\%20Civil\%20Re gistration\%20and\%20Vital\%20Statistics\%20in\%20South\%20Asia\%20Countries\%202019.pdf

UNICEF (2018b). 'With less than 1 in 2 births registered, innovative approaches can boost birth registration in Africa'. 10 August 2018. https://www.unicef.org/esa/press-releases/less-1-2-birthsregistered-innovative-approaches-can-boost-birth-registration-africa

UNICEF (2019). Birth Registration for Every Child by 2030: Are we on track? United Nations Children's Fund. https://data.unicef.org/resources/birth-registration-for-every-child-by-2030/

\section{Key websites}

- United Nations Children's Fund, UNICEF: https://www.unicef.org/protection/birthregistration

- Plan International: https://plan-international.org/early-childhood/birth-registration

\section{Suggested citation}

Idris, I. (2021). Increasing birth registration for children from marginalized groups in Pakistan. K4D Helpdesk Report. Brighton, UK: Institute of Development Studies. DOI: 10.19088/K4D.2021.102

\section{About this report}

This report is based on six days of desk-based research. The K4D research helpdesk provides rapid syntheses of a selection of recent relevant literature and international expert thinking in response to specific questions relating to international development. For any enquiries, contact helpdesk@k4d.info.

K4D services are provided by a consortium of leading organisations working in international development, led by the Institute of Development Studies (IDS), with Education Development Trust, Itad, University of Leeds Nuffield Centre for International Health and Development, Liverpool School of Tropical Medicine (LSTM), University of Birmingham International Development Department (IDD) and the University of Manchester Humanitarian and Conflict Response Institute (HCRI).

This report was prepared for the UK Government's Foreign, Commonwealth and Development Office (FCDO) and its partners in support of pro-poor programmes. Except where otherwise stated, it is licensed for non-commercial purposes under the terms of the Open Government Licence v3.0. K4D cannot be held responsible for errors, omissions or any consequences arising from the use of information contained in this report. Any views and opinions expressed do not necessarily reflect those of FCDO, K4D or any other contributing organisation.

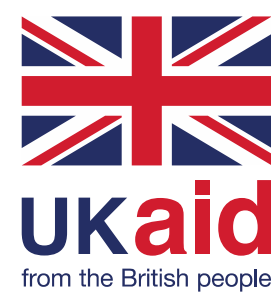

(C) Crown copyright 2021. 